\title{
Kahoot! como instrumento potencializador na participação e engajamento dos alunos na aprendizagem de conceitos de programação
}

\author{
Jamille Anderson Luiz da Silva ${ }^{1}$, Fábio Cristiano Souza Oliveira ${ }^{1}$, \\ Danielle Juliana Silva Martins ${ }^{1}$ \\ ${ }^{1}$ Instituto Federal de educação, Ciência e Tecnologia do Sertão Pernambucano - \\ Campus Petrolina (IF SERTÃO - PE). Departamento de Licenciatura em Computação. \\ Caixa Postal 15.064 - 91.501-970 - Petrolina - PE - Brasil \\ \{jamille.anderson@ifsertao-pe.edu.br,fabio.cristiano@ifsertao-pe.edu.br, \\ danielle.juliana@ifsertao-pe.edu.br
}

Abstract. Faced with the effort to use information and communication technologies (ICT) in the teaching-learning process, it aims to introduce digital tools to promote greater engagement and participation of students. One such tool is Kahoot!, a learning platform that uses digital-based learning for this purpose. Through teaching experiences in programming courses, with this research, it was possible to observe that the Kahoot! functioned as a potentiating instrument for a greater participation and engagement of the students, besides helping to fix concepts related to the logic of programming.

Resumo. Diante do esforço de utilizar as tecnologias da informação e comunicação (TIC) no processo ensino-aprendizagem, objetiva-se inserir ferramentas digitais para promover um maior engajamento e participação de alunos. Uma dessas ferramentas é o Kahoot!, uma plataforma de aprendizagem que utiliza a aprendizagem baseada em jogos digitais para esse propósito. Através de experiências de ensino em cursos de programação, com essa pesquisa, foi possível observar que o Kahoot! funcionou como instrumento potencializador para uma maior participação e engajamento dos estudantes, além de auxiliar na fixação de conceitos relacionados à lógica de programação.

\section{Introdução}

$\mathrm{Na}$ era atual conhecida como da informação, digital ou tecnológica, o ensino tradicional tem passado por diversas mudanças influenciadas pelo fácil e rápido acesso a conhecimentos, permitido principalmente pelo uso de smartphones e/ou notebooks. O uso simples de papel e caneta não é mais interessante a estudantes acostumados a utilizarem nativamente esses dispositivos, conectados à internet, com o uso constante de aplicativos de diferentes funcionalidades e jogos. Esse uso tem influenciado na forma de pesquisar, aprender, de jogar e de se comunicar. Essa mudança de paradigma fez surgir cada vez mais plataformas digitais contidas de elementos que possam contribuir positivamente no ensino.

Faz-se o uso dessas ferramentas digitais principalmente para motivar, engajar e 
potencializar o interesse dos alunos. Dessa forma, muitas delas são constituídas de componentes ou aspectos de jogos baseadas em metodologias ativas ${ }^{1}$, como por exemplo, a Aprendizagem Baseada em Jogos Digitais (digital game-based learning) que é a aplicação de jogos reais em sala de aula com objetivos pedagógicos (AOKI, 2018).

Nesse propósito, jogos e seus componentes são cada vez mais incorporados e aplicados em diversas áreas como na saúde, esportes, educação, setor empresarial, dentre outros. Dessa forma, como exemplo desses mecanismos digitais é o Kahoot!, uma plataforma de aprendizagem gratuita, baseada nessa metodologia, utilizada para criação de jogos de aprendizagem didáticos (KAHOOT!, 2019).

Considerando esse contexto, o presente trabalho analisa as contribuições do Kahoot! como instrumento potencializador de engajamento e interesse dos alunos, em experiências de aprendizagem em programação, além de também analisá-lo como mecanismo de fixação nas revisões de conteúdos.

Para atender os objetivos desta pesquisa, a metodologia utilizada foi de natureza aplicada, de caráter descritiva e abordagem quanti-qualitativa por meio de questionário aplicado aos alunos participantes dos cursos. Para isso, serão apresentadas e descritas as vivências de ensino referidas. Nelas o Kahoot! foi utilizado no final das aulas e em momentos de revisão, tendo fundamental importância para que os alunos pudessem se interessar mais pelo conteúdo de programação, além de se sentirem engajados e mostrarem ter um maior interesse e participação nesse aprendizado.

\section{Fundamentação teórica}

\subsection{Kahoot!}

É uma plataforma de aprendizagem baseada em jogos, multiplataforma e gratuita, utilizada para tornar as aulas divertidas, dinâmicas e interativas na criação de jogos de aprendizagem didáticos para possibilitar uma maior participação, engajamento e em um formato de jogo competitivo (DELLOS, 2015; KAHOOT!, 2019).

Os jogos criados são chamados de "kahoots" e podem ser criados como forma de questionários (quiz) onde há a escolha entre várias respostas, desordem (jumble) onde se arrastam respostas na ordem correta ou pesquisa (survey) onde reúne-se opiniões de uma audiência, conforme mostrado na figura 1 (KAHOOT!, 2019).

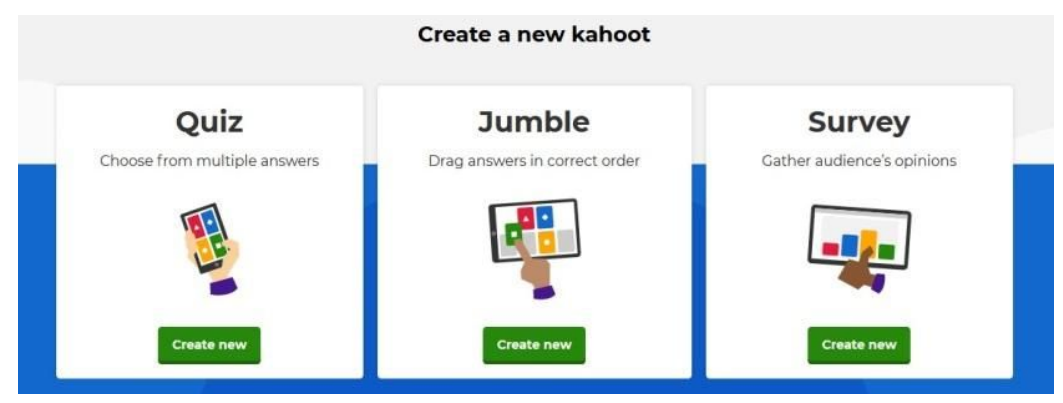

Figure 1. Tipos de Kahoots!. Fonte: https://create.kahoot.it/create\#/new

\footnotetext{
${ }^{1}$ processos de ensino que possibilitam ao aluno ter uma maior participação e responsabilidade em seu aprendizado,
} além de ser protagonista, tendo o professor como guia ( MATTAR, 2017). 
Podem ser jogados pelo smartphone através de aplicativo disponível para sistemas Android e iOS ou por navegadores web (browsers). Para serem criados, utiliza-se o site da ferramenta. Desse modo, não é necessário aos alunos fazerem cadastro na plataforma, basta no início da iteração escolher um nome e entrar no "kahoot" especificado por um código por meio de app ou no indicado em site (KAHOOT!, 2019), como demonstrado na figura 2.

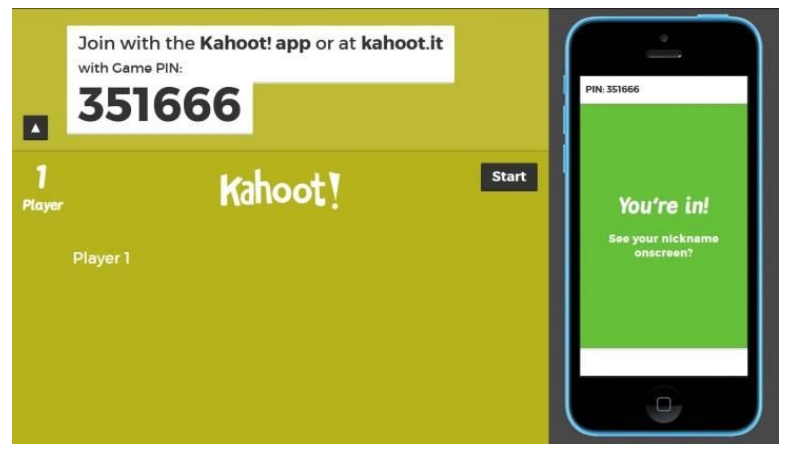

Figure 2. Simulação de entrada no jogo no Kahoot!.

Fonte: https://create.kahoot.it///\#/preview/ea7e6192-d63e-43f8-bfce-217560a158f6

O funcionamento de seus jogos no formato Quiz, que é o mais utilizado, é basicamente na criação de perguntas pelos professores e os alunos escolhem a resposta (ou respostas), a partir de símbolos e cores, cronometradas por um tempo curto.

Pode ser jogado individualmente ou em competição de grupos. Ganha mais pontos quem responder mais rápido e corretamente. Após isso é gerado um ranking na plataforma. Ao fim de cada iteração pergunta-resposta, somam-se pontos a esse ranking. No final de todas as perguntas, o aplicativo já mostra a colocação de todos os alunos e os três primeiros colocados no ranking.

Destaca-se assim o fator competitivo desse recurso digital, pois a cada pergunta-resposta, os indivíduos interagem emocionalmente na perda ou no ganho, além de que é necessário prestar atenção, já que o tempo é umas das peças-chave para vencer no jogo.

\subsection{Aprendizagem baseada em jogos digitais}

Diferente da Gamificação que é, basicamente, o uso de componentes e/ou aspectos de jogos em ambientes que não são jogos com objetivos como motivar e engajar indivíduos na resolução de problemas (ZICHERMANN CUNNINGHAM, 2011), a Aprendizagem Baseada em Jogos Digitais (digital game based-learning) consiste na concepção, desenvolvimento e utilização do jogo em si para fins didáticos e pedagógicos (PRENSKY, 2012; DE CARVALHO, 2015; AOKI, 2018). Exemplificando é utilizar um jogo digital, para auxiliar na aprendizagem em disciplinas específicas. Essa metodologia integra-se aos jogos sérios (serious games), dessa forma, não são utilizados para fins de entretenimento (DE CARVALHO, 2015).

É uma estratégia eficaz para os educadores usarem na sala de aula, pois envolve a resolução de problemas, o pensamento crítico e a fixação de conhecimentos (DELLOS, 2015). Prensky (2012) complementa que essa metodologia se relaciona 
diretamente com o estilo de aprender que a atual geração utiliza por conta da influência dos games na sociedade. Diversos jogos digitais e educacionais são projetados e desenvolvidos para auxiliar em diferentes disciplinas. Esse aspecto mostra a multidisciplinaridade, pois se corretamente for utilizada e adaptada, desenvolve habilidades e competências além de ser um auxílio complementar ao aprendizado (PRENSKY, 2012).

De acordo com seu propósito, é importante destacar que os jogos a serem utilizados precisam necessariamente conter elementos que possam somar ao aprendizado e não tornar a aula desinteressante ou de difícil entendimento. Portanto, o feedback, competição, colaboração, desafios bem delimitados, conteúdo, motivação, engajamento, aprender com erros, devem ser imprescindivelmente observados pelos professores antes da utilização do jogo (DE CARVALHO, 2015). Além desses componentes, é preferível que os jogos tenham uma jogabilidade simples, pois facilita ao professor para a aplicação, quando se tem uma sala de aula com muitos alunos, ao mesmo tempo que ajuda na melhora na experiência aos estudantes.

\section{Desenvolvimento}

Os cursos e a pesquisa foram realizados no IF Sertão-PE (campus Petrolina-PE) no projeto Academia HackTown que é destinado a ensinar a programação em jogos e robótica, para crianças e jovens através de uma seleção pública. Suas turmas são formadas considerando a idade do aluno. A equipe conta com a participação de docentes e discentes de cursos na área da computação. Os cursos são planejados em aspecto de jogo, assim, os módulos são denominados de fases e são utilizados componentes de jogos.

Em cada fase são determinados mil (1000) pontos para serem divididos entre as atividades, e logo após são atribuídas em um ranking online. Cada turma contém sua denominação, objetivos, público-alvo e planejamento específicos. Contudo, o Kahoot! foi utilizado nelas com o mesmo propósito, no formato Quiz, com perguntas sobre os assuntos estudados em programação, como por exemplo, perguntas que focavam a sintaxe ou particularidades, não eram portanto questões de programação na plataforma, anteriormente demonstrada na figura 3. A pontuação conquistada pelos alunos nele era somada ao ranking da turma.

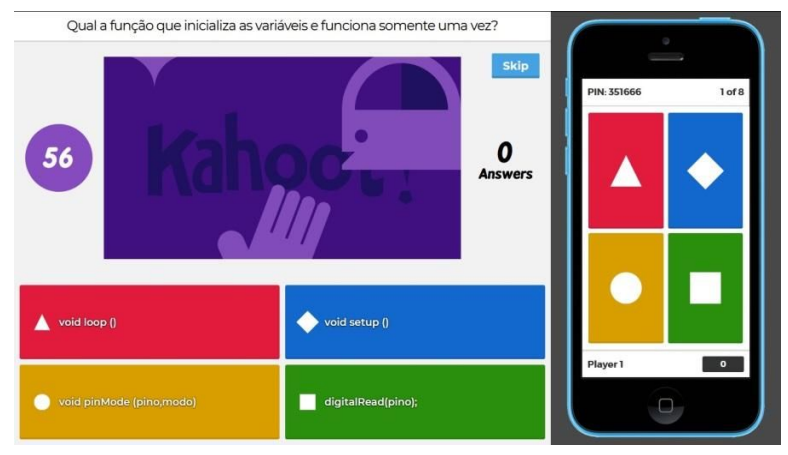

Figure 3. Exemplo de pergunta na forma Quiz no Kahoot!.

Fonte: https://create.kahoot.it/l/\#/preview/ea7e6192-d63e-43f8-bfce-217560a158f6 


\subsection{Turmas TEENS JR}

Nas duas turmas denominadas TEENS JR, estudaram cerca de 30 alunos regularmente matriculados no ensino fundamental, com idade de 13 a 14 anos. Teve carga horária de oitenta horas (80h). Foi dividida e planejada em cinco fases conforme mostrado abaixo:

- Fase 1 - Entrando no Jogo (14h): Conceitos de lógica de programação com Portugol e VisualG.

- Fase 2 - Craftzando (12h): Aprendizagem de programação através da linguagem Python, utilizada remotamente e integralmente com o jogo Minecraft.

- Fase 3 - Explorando o Mobile (10h): Conceitos de desenvolvimento de jogos com o App Inventor.

- Fase 4 - Desafio dos Hackers (18h): Ensino de programação com a linguagem C.

- Fase 5 - Duelo dos Robôs (26h): Ensino da robótica educacional por meio das plataformas LEGO EV3 Mindstorms e Arduino.

As aulas ocorreram com quatro horas (4h) de aula semanais, durante período de 5 meses. O objetivo da turma foi de estimular de forma lúdica o desenvolvimento de habilidades cognitivas necessárias no Século XXI como: raciocínio lógico, raciocínio matemático e algorítmico, sistematização do pensamento, causa e consequência, concentração, decomposição de problemas e, dessa forma, o Pensamento Computacional.

\subsection{Turmas TEENS}

Nas três turmas denominadas TEENS, estudaram cerca de 34 alunos regularmente matriculados nos ensinos fundamental e médio, com idade entre 15 a 17 anos. Teve carga horária de sessenta horas $(60 \mathrm{~h})$ sendo foi dividida e planejada em quatro fases conforme mostrado abaixo:

- Fase 1 - Entrando no Jogo (6h): Conceitos de lógica de programação com Portugol.

- Fase 2 - O Desafio dos Hackers (12h): Ensino de programação com a linguagem C.

- Fase 3 - Explorando a Força WEB (24h): Desenvolvimento de jogo com o framework Phaser utilizando HTML5, CSS3 e Javascript.

- Fase 4 - Hackeando a Arduinolandia (18h): Ensino da robótica educacional através da plataforma Arduino.

As aulas ocorreram em três horas (3h) de aulas semanais, durante o período de 5 meses. O objetivo da turma foi de ampliar o amadurecimento precoce de conhecimentos em relação à lógica para programação, o desenvolvimento web, a programação em $\mathrm{C}$ e conceitos da robótica educacional, desenvolvendo nos jovens o Pensamento Computacional para uma integração de conhecimentos imprescindíveis para adequação ao mercado de trabalho atual além do desenvolvimento de possíveis habilidades.

\section{Metodologia}

Esta pesquisa se configura como uma pesquisa qualitativa e quantitativa, que segundo Figueiredo (2004) é o método que permite a interação entre dados descritivos com dados estatísticos. A convergência das duas abordagens foi definida para possibilitar uma contribuição mais efetiva para compreender fenômenos investigativos na educação, pelo fato de se complementarem (SOUZA; KERBAUY, 2017). 
Qualitativamente, com a interpretação indutiva dos dados através da análise de conteúdo, pôde-se aferir e retratar as contribuições e relações entre os elementos investigados e as experiências de ensino relatadas, com a descrição das opiniões diretas dos participantes (PRODANOV; DE FREITAS, 2013). Quantitativamente, por meio da escala Likert com tradução em números das opiniões e informações coletadas, pôde-se investigar as hipóteses levantadas, assim como as contribuições no processo de mudança das aulas, compreender o processo experimentado pelo grupo de alunos, os benefícios referentes à ferramenta digital para fundamentar e refinar os dados qualitativos (PRODANOV; DE FREITAS, 2013).

O questionário foi estruturado com perguntas abertas e escalonadas, que segundo Prodanov e De Freitas (2013) "são perguntas de múltipla escolha, nas quais as opções são destinadas a captar a intensidade das respostas dos entrevistados", seguindo a escala Likert. Da mesma forma que seguiu a definição das categorias, ampliando o número de perguntas a cada uma como forma de captar atitudes e opiniões objetivas à investigação.

A escala Likert é um método desenvolvido e proposto por Rensis Likert (1932) como forma de "mensurar atitudes no contexto das ciências comportamentais" (JUNIOR; COSTA, 2014). É utilizado para obtenção de respostas de um grupo, a partir de itens (frases) que contém geralmente um número ímpar de alternativas com níveis de concordância, entre concordo totalmente ou discordo totalmente.

O instrumento de coleta de dados foi aplicado a 54 alunos participantes das turmas, com faixa etária entre 13 a 17 anos. Os resultados e discussão dos dados serão apresentados abaixo.

\section{Resultados e discussão}

Conforme o feedback dos alunos participantes, através de suas opiniões diretas e objetivas, serão apresentados e analisados os dados em questão.

Pergunta 1. O que você acha da utilização da plataforma Kahoot para sua aprendizagem?

Respostas: O aluno 33 informou que foi "Uma das melhores formas de aprendizados e para fixar o conhecimento". $O$ aluno 16 complementou que "Essa ferramenta ajuda a fixar o aprendizado das aulas". Para o aluno 38, "faz a gente aprender mais". Já o aluno $32 \mathrm{diz}$ que "Me motivou a aprender para conseguir ganhar". Discussão: As declarações convergem com um dos objetivos, mostrando que funcionou para a fixação e assimilação de conteúdos. Além disso, os fez querer se esforçar para aprender mais para, proporcionalmente, tentar vencer ou melhorar seu desempenho nos "kahoots". Percebe-se com isso que como o funcionamento do Kahoot! como jogo criou motivos para os alunos participarem mais, aprendessem mais e se sentissem mais engajados.

Respostas: Somando às afirmações anteriores, o aluno 19 respondeu que "Por ter uma interface e jogabilidade muito simples, creio que minha mente consegue captar mais informações tanto por esta simplicidade como pela diversão". Para o aluno 48, "É uma plataforma que ajuda a aprender o conteúdo de forma divertida”, e 
isso fez com que, conforme os alunos, eles testassem seus conhecimentos de forma lúdica. Além disso, o aluno 19 destacou a simplicidade ao jogar e que isso o proporcionou se divertir de forma mais fácil. Como informado na subseção 2.2.

Respostas: A resposta do aluno 23 foi que "eu acho que a plataforma kahoot, aumenta a interação entre os alunos, deixa a aula mais dinâmica, além de colocar em prática a competitividade com os mesmos". Discussão: A declaração destaca o propósito da aplicação em vivência de ensino. Através da interação entre os alunos, o dinamismo das aulas e a competição, pode-se ter uma diferente experiência de ensino que esteja mais próxima da realidade dos alunos trazendo-os formas de auxiliar no seu engajamento e interesse pela aula.

Respostas: Já o aluno 52 diz que “Acho ótimo, adoro ficar em primeiro”. Para o aluno 54 diz que "É muito motivador, eu perco varias vezes para todos :)". O aluno 30 informou que “ajuda no espirito competitivo”. Discussão: Pode-se dizer que a competição é inevitável quando se joga de forma coletiva. Essas afirmações mostram isso pois, quando se tem um jogo, que contém pontuação e ranking e sua mecânica, e é jogado por todos, haverá então um esforço para conquistar mais pontos e ultrapassar os colegas. O Kahoot! cria esse cenário conforme destacados na subseção 2.1.

Respostas: Os outros alunos simplificaram dizendo: "Boa, poderia ter em todas as aulas", "Bom", "Divertida", “é bem divertido", "Excelente”, “Inovadora", "Legal”, “muito boa”, "Muito bom nada contra", “muito divertida”, "muito legal”, “Ótima”, "SIMPLESMENTE boa” e "Super divertida”. Discussão: Essas declarações mostram um feedback positivo com o uso do Kahoot! nas aulas.

Pergunta 2. Qual o elemento do Kahoot que você mais gostou? A posição no ranking? A pontuação? A competição? Comente

Respostas: Referente ao questionado (Pergunta 2), Para o aluno 45 foi: “A competição, pois é o que deu e dá sentido à sua posição em relação aos outros”. O aluno 35 explanou, "A competição de quem consegue acertar mais coisas e de quem consegue acertar mais perguntas em menos tempo". O aluno 26 complementou que “A competição, pois a pessoa fica ansiosa com as pergunta”. Já, o aluno 50 respondeu que foi "A competição, uma vez que ao competir, os assuntos das aulas ficam mais fáceis de entender". Para o aluno 8 foi “A posição no ranking a competição porque fica na frente dos outros". Outros 25 alunos, responderam simplesmente que foi a " $\boldsymbol{A}$ competição", e os alunos 20 e 43 completaram dizendo que foi "A competitividade".

Discussão: Como observado a competição foi o ponto chave de identidade e engajamento com a ferramenta, além de funcionar como o impulsionador para os alunos estudarem mais os conteúdos para galgar uma melhor posição no ranking do Kahoot! e da turma, conquistando mais e melhores pontuações. A competição pode ser discutida em duas óticas. Uma é observar ela como algo positivo, em um nível saudável que motiva na ação de jogar e querer estar em disputa com seus colegas. Outra é de que uma forte competição pode gerar desavenças, brigas, discussões, dentre outros. Contudo, com o observado nas respostas, os alunos gostaram de estar em um ambiente competitivo e isso os influenciou positivamente. Além disso, destaca-se o forte espírito de competição nos alunos onde que, sempre estavam a tentar ultrapassar a pontuação, demonstrando engajamento com o cenário. 
Respostas: Considerando isso, ao complementar as respostas anteriores, os alunos 18, 12, 27 e 48 foi: “A pontuação", sendo complementado pelo aluno 47 que destacou "As pontuações". Já o aluno 38 diz que "é um jogo legal e oque eu mais gostei foi o ranking". O aluno 19 respondeu que "Os gritos que quase quebram as janelas!”. Para os alunos 1, 13, 14, 22 e 42 foi: “A posição no ranking”, sendo respondido pelo aluno 51 que destacou "Ranking". Para o aluno 49 foi a "A dinâmica da pontuação". Os alunos 17, 36, 40, 11 e 5 foram respectivamente: "ranking $\boldsymbol{e}$ a pontuação e competição", “a pontuação e a competição", “As 3 alternativas", “competição Pontuação" $e$ "tudo".

Discussão: Essas afirmações convergem com o propósito de entregar o feedback, ao demonstrar o desempenho dos alunos por meio dos pontos obtidos e a atualização do ranking, que são elementos de jogos que engajam e motivam com a satisfação pessoal ao conquistar esses elementos e observar seu desempenho. Especificamente com a resposta do aluno 19, percebe-se que existiu um envolvimento emocional pois a "gritaria" dos alunos, demonstra o engajamento dos alunos ao jogar pois criou -se uma agitação pela vontade de vencer no jogo.

Respostas: Por fim, O aluno 7 simplificou que foi “a diversao”. Discussão: A diversão é um ponto importante que deve ser considerado para uma experiência com jogos tenha sucesso. Com isso, o engajamento, motivação e participação dependem de que o jogo seja divertido.

\section{Pergunta 3. Você joga algum tipo de jogo digital? Se sim com que frequência?}

Respostas: Ao serem perguntados se jogavam e em qual frequência (Pergunta 3), 57,4\% dos alunos, sendo a maioria $(n=31)$, jogam algum tipo de jogo digital em constante frequência, "diariamente" ou "semanalmente". Já 35,\% dos alunos $(n=19)$ jogam "de vez em quando". Contudo, 7,4\% deles $(n=4)$ não costumam jogar. Isso vai de acordo de que os jogos digitais fazem parte do cotidiano da maioria dos jovens na atualidade que o jogam em certa constância, e isso influencia em sua forma de aprendizado, pois estão acostumados com componentes, dinâmica e mecânica contidos nos jogos.

\section{Pergunta 4. Em qual dispositivo você mais joga?}

Respostas: Na questão sobre qual dispositivos eles mais jogavam (Pergunta 4), $51,9 \%$ dos alunos $(n=28)$, sendo assim a maioria, jogam pelo "smartphone". O "computador" foi apontado como o segundo dispositivo mais utilizado na resposta de $42,6 \%$ dos alunos $(n=23)$. Alguns poucos $(n=2)$ responderam que jogam em "consoles de videogame" e "tablet" $(n=1)$. Discussão: Isso demonstra que a evolução tecnológica em celulares oportunizou disponibilizar atualmente aos clientes, formas de jogar, nesses dispositivos que são acessados geralmente pela maior parte do dia pelas pessoas. Além disso, o computador, que também não foi construído para esse propósito, ultrapassaram até mesmo os consoles de videogame por serem tecnologias mais acessíveis. Com isso, mostra o crescimento de acesso aos jogos digitais em diferentes dispositivos. 
Afirmação 1. O Kahoot! é uma ferramenta que motiva a assimilação dos conteúdos através do seu uso ao fim da aula pelo seu aspecto de jogo.

Respostas: Na questão sobre a assimilação/fixação de conteúdos (Afirmação 1), a maioria absoluta $98,2 \%$ dos alunos $(n=53)$ concordaram que o Kahoot! funciona no auxílio da assimilação ou fixação de conteúdos pelo seu aspecto de game. Discussão: Assim, eles praticaram teoricamente o que se aprendeu na sala de aula. Além disso, não foi percebida qualquer discordância ao questionado já que apenas um aluno não concordou nem discordou com a afirmação.

Afirmação 2. O uso do Kahoot! nas aulas, com a sua atribuição de pontos, faz o aluno prestar mais atenção nas aulas para vencer no jogo e aprender ao mesmo tempo.

Respostas: Sobre o esforço em aprender e jogar ao mesmo tempo (Afirmação 2), a maioria absoluta $98,2 \%$ dos alunos $(n=53)$ concordaram com o proposto. Além disso, não foi percebida qualquer discordância ao questionado já que apenas um aluno não concordou nem discordou com a afirmação. Discussão: As respostas dos alunos mostram que concordam que o Kahoot! funciona para auxiliar no aumento da sua participação e no seu interesse pelo seu aspecto de game que os impulsionam a estudar mais para tentar vencer nas partidas.

\section{Afirmação 3. A ferramenta Kahoot! proporciona a aula dinamicidade, interatividade e diversão pelo seu aspecto de jogo.}

Respostas: Ao serem questionados sobre o impacto do funcionamento do Kahoot! (Afirmação 1) que contém aspecto de jogo, nas aulas, 96,3\% dos alunos ( $n=$ 52) concordaram. Houve um aluno que discordou parcialmente e um que não concordou nem discordou com a afirmação. Discussão: Dessa forma, os dados mostram que essa ferramenta proporcionou diversão, dinamismo e interatividade à aula, demonstrando que eles se sentiram-se engajados e motivados em aprender dessa forma.

\section{Conclusão}

A aplicação de jogos em sala de aula é considerada uma boa prática docente pois oportuniza um aprendizado participativo, divertido, dinâmico e engajador (DELLOS, 2015). A presente pesquisa apresentou relatos de experiência de ensino na aprendizagem de conceitos em programação em que o Kahoot!, que funciona como jogo, foi utilizado com os objetivos de potencializar a participação, interesse e engajamento dos alunos participantes, além de estimulá-los a buscar aprender mais por meio da fixação de conhecimentos de forma lúdica.

Em virtude dos dados obtidos por meio do feedback dos alunos, foi percebido que esses objetivos foram alcançados, o que permite concluir que os estudantes sentiram-se mais interessados, engajados e motivados em aprender os conceitos de programação nesse formato. Um dos fatores impulsionadores disso foi a competição, que por conta das pontuações e ranking, contidos na plataforma, influenciaram nas ações dos alunos para se esforçar a aprender mais conceitos de programação para conquistar mais pontos e conseguir uma melhor colocação. 
Conforme o conceito de Aprendizagem Baseada em Jogos Digitais presentes na subseção 2.2, o Kahoot! não foi utilizado com o objetivo de entretenimento, mas sim para objetivos pedagógicos para sanar problemas observados em ambientes de ensino como o desinteresse que desencadeia outros como a falta de engajamento, falta de motivação no ato de aprender.

Essa pesquisa foi submetida e aprovada pelo Comitê de Ética em Pesquisa com Seres Humanos (CEP) com o título: Academia Hacktown: $1^{\text {a }}$ Escola Pública de Programação de Jogos e Robótica do Brasil, sob o número CAAE (Certificado de Apresentação para Apreciação Ética) 74378217.7.0000.8052 e está inserida na linha de pesquisa pensamento computacional que vem sendo desenvolvida pelo grupo de pesquisa GET (Grupo de Estudos e Pesquisas em Educação e Tecnologias).

\section{Referências}

AOKI, Ricardo Luiz. Aprendizagem baseada em jogos digitais para o ensino de redação jornalística: um estudo de caso da narrativa digital aplicada no newsgame Aprendendo Jornalismo. UFSC. 2018.

DE CARVAlHO, Carlos Vaz. Aprendizagem baseada em jogos-Game-Based Learning. In: II World Congress on Systems Engineering and Information Technology. 2015. p. 176-181.

DELLOS, Ryan. Kahoot! A digital game resource for learning. International Journal of Instructional Technology and Distance Learning, v. 12, n. 4, p. 49-52, 2015.

FIGUEIREDO, Nébia Maria Almeida de et al. Método e metodologia na pesquisa científica. São Paulo: Difusão, 2004.

JUNIOR, Severino; COSTA, Francisco. Mensuração e escalas de verificação: uma análise comparativa das escalas de Likert e Phrase Completion. PMKT-Revista Brasileira de Pesquisas de Marketing, Opinião e Mídia, v. 15, p. 1-16, 2014.

KAHOOT! Game-based blended learning \& classroom response system. Disponível em: <https://kahoot.com/what-is-kahoot/>. Acesso em: 24 mar. 2019.

MATTAR, João. Metodologias Ativas: para a educação presencial, blended e a distância. São Paulo: Artesanato Educacional, 2017.

PRENSKY, Marc. Aprendizagem baseada em jogos digitais. São Paulo: Editora Senac São Paulo, 2012.

PRODANOV, Cleber Cristiano; DE FREITAS, Ernani Cesar. Metodologia do Trabalho Científico: Métodos e Técnicas da Pesquisa e do Trabalho Acadêmico. $2^{\mathrm{a}}$ Edição. Editora Feevale, 2013.

SOUZA, Kellcia Rezende; KERBAUY, Maria Teresa Miceli. Abordagem quanti-qualitativa: superação da dicotoamia quantitativa-qualitativa na pesquisa em educação. Educação e Filosofia, v. 31, n. 61, 2017.

ZICHERMANN, Gabe; CUNNINGHAM, Christopher. Gamification by design: Implementing game mechanics in web and mobile apps. "O'Reilly Media, Inc.", 2011. 